\title{
WEAK CONTINUITY AND STRONGLY CLOSED SETS
}

\author{
D.A. ROSE \\ Department of Mathemtics \\ Francis Marion College \\ Florence, South Carolina 29501 U.S.A. \\ (Received May 4, 1984)
}

ABSTRACT. After demonstrating the usual product theorems for weakly continuous functions, strongly closed and extremely closed subsets are contrasted to support the conjecture that a product of faintly continuous functions need not be faintly continuous. Strongly closed sets are used to characterize Hausdorff spaces and Urysohn spaces, and with these characterizations two results obtained by $T$. Noiri are obtained by functiontheoretic means rather than by point-set method.

KEY WORDS AND PHRASES. weak continuity, faint continuity, subweak continuity, strongly closed sets.

1980 MATHEMATICS SUBJECT CLASSIFICATION CODE。 54 C 10.

1. INTRODUCTION

Takashi Noiri proved: 1) Every weakly continuous function into a hausdorff space has a closed graph [1] and 2) Every weakly continuous injection into a Urysohn space has a Hausdorff domain [2]. The first of these has been shown true assuming only subweak continuity for the function whereas the second is not generally true for subweakly continuous function [3]. We will obtain Noiri's results bv maping methods via strongly closed sets. But first productivity is discussed for weak continuity, faint continuity and subweak continuity.

2. DEFINITIONS AND NOTATION.

By $\mathrm{f}: \mathrm{X} \rightarrow \mathrm{Y}$ is meant an arbitrary function between arbitrary topological spaces. If $A \subseteq X$, the interior and closure of $A$ are denoted Int $A$ and $C 1 A$ respectively. The topology for a space $X$ may be written $T(X)$. A subset $B$ of a space $Y$ is 0 -open if it contains a closed neighborhood of each of its points. The collection of $\theta$-open sets in $Y$ form a subtopology for $Y$ called the $\theta$-subtopology and denoted $T_{\Theta}(Y)$. By $Y_{\Theta}$ is meant the set $Y$ equipped with the $\theta$-subtopology.

Note 1. For any space $Y, Y=Y_{\Theta}$ if and only if $Y$ is regular. Complements of $\Theta-$ open sets are called $\Theta$-closed and have been studied in connection with H-closed spaces [4], [5], [6]. Finally, for any space $X, D(X)$ denotes the diagonal of $X x$. 
Definition 1. (Levine [7]). A function $\mathrm{f}: \mathrm{X} \rightarrow \mathrm{Y}$ is weakly continuous if $\mathrm{f}^{-1}(\mathrm{~V}) \subseteq$ Int $\mathrm{f}^{-1}(\mathrm{C} 1 \mathrm{~V})$ for each $\mathrm{V} \in \mathrm{T}(\mathrm{Y})$.

Definition 2. (Long and Herrington [8]). A function $f: X \rightarrow Y$ is faintly continuous if $\mathrm{f}^{-1}(\mathrm{~V}) \in \mathrm{T}(\mathrm{X})$ for each $\mathrm{V} \in \mathrm{T}(\mathrm{Y})$.

Note 2. A function $\mathrm{f}: \mathrm{X} \rightarrow \mathrm{Y}$ is faintly continuous if and only if $\mathrm{f}: \mathrm{X} \rightarrow \mathrm{Y}_{\theta}$ is continuous [8].

Definition 3. (Rose [9]). A function $f: X \rightarrow Y$ is subweakly continuous if there is an open basis $B$ for $T(Y)$ such that $C 1 f^{-1}(V) \subseteq f^{-1}(C 1 V)$ for each $V \varepsilon B$.

To have a proper perspective of the above defined classes of functions, recall that a function $\mathrm{f}: \mathrm{X} \rightarrow \mathrm{Y}$ is almost rontinunus (in the sense of Singal and Singal [10] if $\mathrm{f}^{-1}(\mathrm{~V}) \varepsilon \mathrm{T}(\mathrm{X})$ for each $\mathrm{V} \varepsilon \mathrm{T}_{S}(\mathrm{Y})$, where $T_{S}(\mathrm{Y})$ is the semiregular subtopology of $\mathrm{T}(\mathrm{Y})$ generated by the regular open sets in $T(Y)$. Also a function $f: X \rightarrow Y$ is called $\Theta$-continuous [1] if for each $x \varepsilon X$ and $V \varepsilon T(Y)$ with $f(X) \varepsilon V$, there is a neighborhood $\mathrm{U}$ of $\mathrm{x}$ with $\mathrm{f}(\mathrm{Cl} \mathrm{U}) \subseteq \mathrm{Cl} \mathrm{V}$. The following implication diagram is pieced together from $[1],[8]$, and $[9]$.

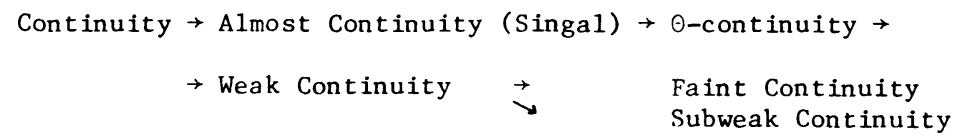

In this diagram no implication is reversible in general though for functions into regular spaces, faint continuity implies continuity. Example 2 of [8] actually shows that faint continuity does not imply subweak continuity and the example below will show the impossibility of the reverse implication even if the range space is discrete (and hence regular).

Example 1. Let $X$ be a $T_{1}$, non $-T_{2}$ space, let $Y$ be the set $X$ with discrete topology and let $\mathrm{f}: \mathrm{X} \rightarrow \mathrm{Y}$ be the identity function. Then $\mathrm{f}$ is subweakly continuous using the open basis of singleton subsets of $Y$ but not faintly continuous since $Y=Y_{\Theta}$ and $f$ is not continuous. For later reference, note that $f$ is injective, $Y$ is $T_{2 \frac{1}{2}}$, and $D(X)=(f \times f)^{-1}(D(Y))$ is not closed in $X \times X$.

The class of $\theta$-continuous functions is closed under composition but generally classes of generalized-continuous functions are not closed under composition even when one of the functions being composed is continuous. Noiri [12] gave an example of an almost continuous (Singal) function $f: X \rightarrow Y$ and a continuous function $g: Y \rightarrow Z$ for which $\mathrm{g} \circ \mathrm{f}$ is not almost continuous (Singal). It is clear, however, that composition of functions from these two classes in the reverse order does produce an almost continuous (Singa1) function. Also, compositions, $f \circ g$, of subweakly (faintly) continuous functions are subweakly (faintly) continuous if $g$ is continuous. The following example shows that a composition of two weakly continuous (and hence subweakly continuous) functions may fail to be subweakly continuous, and thus fail to be weakly continuous.

Example 2. Let $X=\{a, b\}$ with $T(X)=\{\emptyset, X,\{b\}\}, Y=Z=\{a, b, c\}$ with $T(Y)=\{\emptyset, Y,\{a, c\},\{b, c\},\{c\}\}$, and $T(Z)=\{\emptyset, Z,\{a\},\{b\},\{a, b\}\}$. Also let $f: X \rightarrow Y$ and $g: Y \rightarrow Z$ be the inclusion functions. Then $f$ and $g$ are weakly continuous but $g \circ f$ is not even subweakly continuous. 
The following result will be useful for investigating properties of products of weakly continuous functions.

Lemma 1. If $\mathrm{f}: \mathrm{X} \rightarrow \mathrm{Y}$ and $\mathrm{g}: \mathrm{Y} \rightarrow \mathrm{Z}$ are weakly continuous and either $\mathrm{f}$ or $\mathrm{g}$ is continuous, then $\mathrm{g} \circ \mathrm{f}: \mathrm{X} \rightarrow \mathrm{Z}$ is weakly continuous.

Proof: Suppose first that $\mathrm{f}: \mathrm{X} \rightarrow \mathrm{Y}$ is continuous and $\mathrm{g}: \mathrm{Y} \rightarrow \mathrm{Z}$ is weakly continuous. For $V \in T(Z),(g \circ f)^{-1}(V)=f^{-1}\left(g^{-1}(V)\right) \subseteq f^{-1}\left(\right.$ Int $\left.g^{-1}(C 1 V)\right) \subseteq$ Int $f^{-1}\left(g^{-1}(C 1 V)\right)=$ Int $(g \circ f)^{-1}(\mathrm{Cl} V)$ so that $g \circ f: X \rightarrow Z$ is weakly continuous. Now suppose that $\mathrm{f}: \mathrm{X} \rightarrow \mathrm{Y}$ is weakly continuous and $\mathrm{g}: \mathrm{Y} \cdot \mathrm{Z}$ is continuous. If $\mathrm{V} F \mathrm{~T}(\mathrm{Z}),\left(\mathrm{g} \mathrm{o}^{\mathrm{f}}\right)^{-1}(\mathrm{~V})=$ $\left(f^{-1}\left(g^{-1}(V)\right) \subseteq \operatorname{lnt} f^{-1}\left(C 1 g^{-1}(V)\right) \subseteq \operatorname{Int~} f^{-1}\left(g^{-1}(C 1 V)\right)=\operatorname{Int}(g \circ f)^{-1}(C 1 V)\right.$, and henct $\mathrm{g} \circ \mathrm{f}: \mathrm{X} \rightarrow \mathrm{Z}$ is weakly continuous.

Corollary 1. If $\mathrm{f}: \mathrm{X} \rightarrow \mathrm{Y}$ and $\mathrm{g}: \mathrm{Y} \rightarrow \mathrm{Z}$ are weakly continuous functions then 1) $g \circ f$ is (weakly) continuous if ( $Y) Z$ is regular.

Lemma 2. If $g \circ f$ is weakly continuous and $f$ is an open surjection then $g$ is weakly continuous.

Proof: If $\mathrm{f}: \mathrm{X} \rightarrow \mathrm{Y}, \mathrm{g}: \mathrm{Y} \rightarrow \mathrm{Z}$, and if $\mathrm{W} \subseteq \mathrm{Z}$ is open then by the weak continuity of $\mathrm{g} \circ \mathrm{f}, \mathrm{f}^{-1}\left(\mathrm{~g}^{-1}(\mathrm{~W})\right) \subseteq$ Int $\mathrm{f}^{-1}\left(\mathrm{~g}^{-1}(\mathrm{C} 1 \mathrm{~W})\right)=\mathrm{U}$. Since $\mathrm{f}$ is an open surjection, $\mathrm{g}^{-1}(\mathrm{~W})=$ $\mathrm{f}\left(\mathrm{f}^{-1}\left(\mathrm{~g}^{-1}(\mathrm{~W})\right)\right) \subseteq \mathrm{f}(\mathrm{U}) \subseteq$ Int $\mathrm{g}^{-1}(\mathrm{Cl} \mathrm{W})$ so that $\mathrm{g}$ is weakly continuous.

Lemma 3. If $\mathrm{f}: \mathrm{X} \rightarrow \mathrm{Y}$ and $\mathrm{B}$ is an open basis for the topology on $\mathrm{Y}$, $\mathrm{f}$ is weakly continuous if and on $1 \mathrm{y}$ if $\mathrm{f}^{-1}(\mathrm{~V}) \subseteq$ Int $\mathrm{f}^{-1}(\mathrm{Cl} \mathrm{V})$ for each $\mathrm{V} \varepsilon \mathrm{B}$.

Proof: The necessity is clear. For the sufficiency, let $W \in T(Y)$. Then $\mathrm{W}=\mathrm{UV} \mathrm{V}_{\mathrm{a}}$ where each $\mathrm{V}_{\mathrm{a}} \varepsilon \mathrm{B}$. So $\mathrm{f}^{-1}(\mathrm{~W})=\mathrm{Uf}^{-1}\left(\mathrm{~V}_{\mathrm{a}}\right) \subseteq \mathrm{U}$ Int $\mathrm{f}^{-1}\left(\mathrm{Cl} \mathrm{V}_{\mathrm{a}}\right) \subseteq$ Int $\mathrm{U}$ $\mathrm{f}^{-1}\left(\mathrm{Cl} \mathrm{V}_{\mathrm{a}}\right)=\operatorname{Int} \mathrm{f}^{-1}\left(\mathrm{U} \mathrm{Cl} \mathrm{V}_{\mathrm{a}}\right) \subseteq \operatorname{Int} \mathrm{f}^{-1}\left(\mathrm{C} 1 \mathrm{U} \mathrm{V}_{\mathrm{a}}\right)=\operatorname{Int} \mathrm{f}^{-1}(\mathrm{C} 1 \mathrm{~W})$.

3. PRODUCT THEOREMS.

In this section, the product theorems proven in [10], [12], and [13], for almost continuous functions (in the sense of Singal and Singal) and in [14] for $\theta$-continuous functions, will be shown to hold for weakly continuous functions. Also a stronger product theorem will be proven for subweakly continuous functions than that found in [3].

Theorem 1. Let $\left\{\mathrm{f}_{\mathrm{a}}: \mathrm{X}_{\mathrm{a}} \rightarrow \mathrm{Y}_{\mathrm{a}} \mid \varepsilon \mathrm{A}\right\}$ be a family of functions. Then $\Pi \mathrm{f}_{\mathrm{a}}:$ $\pi \mathrm{x}_{\mathrm{a}} \rightarrow \pi \mathrm{Y}_{\mathrm{a}}$ is weakly continuous if and on $1 \mathrm{y}$ if each $\mathrm{f}_{\mathrm{a}}$ is weakly continuous.

Proof: For the sufficiency, suppose each $f_{a}$ is weakly continuous and let $\mathrm{V}=\pi \mathrm{V}_{\mathrm{a}} \subseteq \pi \mathrm{Y}_{\mathrm{a}}$ be a basic open set. That is, each $\mathrm{V}_{\mathrm{a}} \subseteq \mathrm{Y}_{\mathrm{a}}$ is open and for all but finitely many $a, V_{a}=Y_{a}$. Let $f=\pi f_{a}$. Then $f^{-1}(V)=\pi f_{a}^{-1}\left(V_{a}\right) \subseteq \pi$ Int $f_{a}^{-1}$

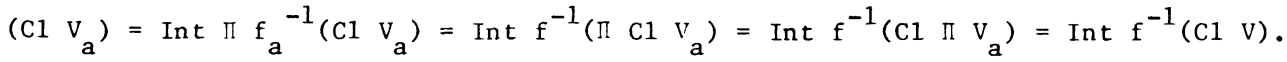
By Lemma 3, $f=\pi f_{a}$ is weakly continuous. For the necessity, suppose that $f=\Pi f_{a}$ is weakly continuous. Then for each a, $f_{a} \circ P_{a}=Q_{a} \circ f$ is weakly continuous by Lemma 1 , where $\mathrm{P}_{\mathrm{a}}: \mathrm{IX}_{\mathrm{a}} \rightarrow \mathrm{X}_{\mathrm{a}}$ and $\mathrm{Q}_{\mathrm{a}}: \Pi \mathrm{Y}_{\mathrm{a}} \rightarrow \mathrm{Y}$ are the projections. Since $\mathrm{P}_{\mathrm{a}}$ is an open surjection, $f_{a}$ is weakly continuous by Lemma 2 .

Theorem 2. The function $f: X \rightarrow \Pi Y_{a}$ is weakly continuous if and only if each $\mathrm{P}_{\mathrm{a}} \circ \mathrm{f}$ is weakly continuous.

Proof: The necessity follows from Lemma 1 since the projection $\mathrm{P}_{\mathrm{a}}: \Pi_{\mathrm{a}} \mathrm{Y}_{\mathrm{a}} \mathrm{Y}_{\mathrm{a}}$ is continuous. For the sufficiency let $x_{a}=X$ for each a and let $d: X \rightarrow \pi x_{a}$ be the continuous diagonal map. Then $\pi\left(P_{a} \circ f\right)$ is weakly continuous by Theorem 1 so that $\mathrm{f}=\left[\Pi\left(\mathrm{P}_{\mathrm{a}} \circ \mathrm{f}\right)\right] \circ \mathrm{d}$ is weakly continuous by Lemma 1 . 
Corollary 2. Let $\left\{f_{a}: X \rightarrow Y_{a} \mid a \in A\right\}$ be a family of functions. The function $f: X \rightarrow \Pi Y_{a}$ defined by $f(x)=\left\{f_{a}(x)\right\}$, is weakly continuous if and only if each $f_{a}$ is weak1y continuous.

Proof: For each a, $\mathrm{P}_{\mathrm{a}}$ O $\mathrm{f}=\mathrm{f}_{\mathrm{a}}$.

Theorem 3. If $\mathrm{f}_{a}: \mathrm{X}_{a} \rightarrow \mathrm{Y}_{a}$ is subweakly continuous for each $a \in A$ then $\mathrm{f}=\mathrm{II}_{\mathrm{a}}$ is subweakly continuous.

Proof: Let $B_{a}$ be an open basis for the topology on $Y_{a}$ for each a $\varepsilon A$. Let $B=\left\{\pi V_{a} \mid V_{a}=Y_{a}\right.$ for all but finitely many $a \in A$ and $V_{a} \varepsilon B_{a}$ otherwise $\}$ Then $B$ is an open basis for the product topology on $\pi Y_{a}$ and for each $\Pi V_{a} \varepsilon B, C 1 f^{-1}\left(\pi V_{a}\right)=$ $\mathrm{C} 1 \pi \mathrm{f}_{\mathrm{a}}^{-1}\left(\mathrm{~V}_{\mathrm{a}}\right)=\pi \mathrm{Cl} \mathrm{f}_{\mathrm{a}}^{-1}\left(\mathrm{~V}_{\mathrm{a}}\right) \subseteq \Pi \mathrm{f}_{\mathrm{a}}^{-1}\left(\mathrm{Cl} \mathrm{V}_{\mathrm{a}}\right)^{\mathrm{a}}=\mathrm{f}^{-1}\left(\pi \cdot \mathrm{Cl} \mathrm{V}_{\mathrm{a}}\right)=\mathrm{f}^{-1}\left(\mathrm{Cl} \Pi \mathrm{V}_{\mathrm{a}}\right)$ so that $\mathrm{f}=\Pi \mathrm{f}_{\mathrm{a}}$ is subweakly continuous.

Theorem 4. The function $f: X \rightarrow \pi Y_{a}$ is subweakly continuous if each $P_{a} \circ$ is subweakly continuous.

Proof: Let $\mathrm{X}_{\mathrm{a}}=\mathrm{X}$ for each $\mathrm{a}$, and let $\mathrm{d}: \mathrm{X} \rightarrow \pi \mathrm{X}_{\mathrm{a}}$ be the continuous diagonal

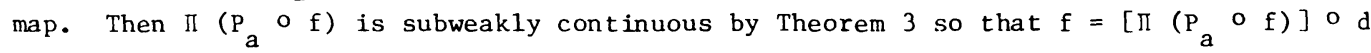
is subweakly continuous.

Corollary 3. ([3]) If $\mathrm{f}_{\mathrm{a}}: \mathrm{X} \rightarrow \mathrm{Y}_{\mathrm{a}}$ is subweakly continuous for each a $\varepsilon \mathrm{A}$ then $f: X \rightarrow \Pi Y_{a}$ defined by $f(x)=\left\{f_{a}(x)\right\}$, is subweakly continuous.

Proof: For each a $\varepsilon$ A, $\mathrm{P}_{\mathrm{a}} \circ \mathrm{f}=\mathrm{f}_{\mathrm{a}}$.

4. STRONGLY CLOSED SETS.

The notion of a strongly closed subset of a product space will be introduced generalizing the notions of a $\Theta$-closed set [4] and of a strongly closed graph of a function [15]. The notion of an extremely closed set will be introduced generalizing the notion of an extremely closed graph of a function [8]. Using these notions, some product-type theorems will be obtained for faintly continuous functions.

Definition 4. Let $\left\{\mathrm{Y}_{\mathrm{a}} \mid \mathrm{a} \varepsilon \mathrm{A}\right\}$ be a family of spaces. A subset $\mathrm{E} \subseteq \Pi \mathrm{Y}_{\mathrm{a}}$ is strongly closed with respect to $B \subseteq A$ (or with respect to the factor $\Pi_{a}$, $a \varepsilon B$ ) if for each $y \in$ ( $I \mathrm{Y}_{\mathrm{a}}$ ) $-\mathrm{E}$, there is a basic open set $\Pi \mathrm{V}_{\mathrm{a}}$ containing $\mathrm{y}$ such that if $\mathrm{W}_{\mathrm{a}}=\mathrm{Cl} \mathrm{V}_{\mathrm{a}}$ for $\mathrm{a} \varepsilon \quad \mathrm{B}$ and $\mathrm{W}_{\mathrm{a}}=\mathrm{V}_{\mathrm{a}}$ otherwise, then (I $\left.\mathrm{W}_{\mathrm{a}}\right) \cap \mathrm{E}=\emptyset$. If $\mathrm{E}$ is strongly closed with respect to $B=A, E$ is said to be totally strongly closed.

Definition 5. Let $\left\{\mathrm{Y}_{\mathrm{a}} \mid \mathrm{a} \varepsilon \mathrm{A}\right\}$ be a family of spaces. A subset $E \subseteq \Pi \mathrm{Y}_{\mathrm{a}}$ is extremely closed with respect to $B \subseteq A$ (or with respect to the factor $\pi Y_{a}$, $a \varepsilon B$ ) if for each y $\varepsilon$ ( $\left.\Pi \mathrm{Y}_{\mathrm{a}}\right)$-E there is a basic open set $\Pi \mathrm{V}_{\mathrm{a}}$ containing $\mathrm{y}$ with $\mathrm{V}_{\mathrm{a}} \varepsilon \mathrm{T}_{\Theta}\left(\mathrm{Y}_{\mathrm{a}}\right)$ for each a $\varepsilon A$ and such that $\left(\Pi V_{a}\right) \cap E=\emptyset$. If $E$ is extremely closed with respect to $B=A, E$ is said to be totally extremely closed.

Note 3. The family of complements of the strongly (extremely) closed sets with respect to $B \subseteq A$ is a subtopology of $T\left(\pi Y_{a}\right)$, the product topology. And extremely closed with respect to $\mathrm{B} \subseteq \mathrm{A}$ implies strongly closed with respect to $\mathrm{B} \subseteq \mathrm{A}$.

Note 4. The subtopology of complements of the totally strongly closed sets is $\mathrm{T}_{\Theta}\left(\Pi \mathrm{Y}_{\mathrm{a}}\right)$ and $\mathrm{T}\left(\Pi\left(\mathrm{Y}_{\mathrm{a}}\right)_{\Theta}\right)$, the product topology with the $\Theta$-topology on each factor space, is the subtopology of complements of the totally extremely closed sets. Thus, $\mathrm{T}\left(\Pi\left(\mathrm{Y}_{\mathrm{a}}\right)_{\Theta}\right) \subseteq \mathrm{T}_{\Theta}\left(\pi \mathrm{Y}_{\mathrm{a}}\right)$. 
Note 5. Since $\Pi Y_{a}$ is regular if and only if each $Y_{a}$ is regular, $T_{\Theta}\left(\Pi Y_{a}\right)=T\left(\Pi Y_{a}\right)$ implies that $T_{\Theta}\left(Y_{a}\right)=T\left(Y_{a}\right)$ for each a which in turn implies that $T\left(\Pi Y_{a}\right)=T\left(\Pi\left(Y_{a}\right){ }_{\Theta}\right)=$ $\mathrm{T}_{\Theta}\left(\pi \mathrm{Y}_{\mathrm{a}}\right)$. The next example shows that in general, $\mathrm{T}\left(I\left(\mathrm{Y}_{\mathrm{a}}\right)_{\Theta}\right) \notin \mathrm{T}_{\Theta}\left(\pi \mathrm{Y}_{\mathrm{a}}\right)$. By the above remarks, this proper inclusion requires at least one non-regular $Y_{a}$ so that

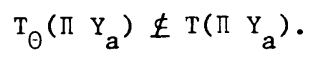

Example 3. Let $R$ be the set of real numbers, $X=(0,2) \subseteq R$ and $Y=[0,2) \subseteq R$. Let $H_{r}=U_{n} \geq r\left(\frac{1}{2 n+1},-\frac{1}{2 n}\right)$ for $r \varepsilon N=\{1,2,3, \ldots\}$ and let $C_{r}=U_{n} \geq$ $r\left(\frac{1}{2 n+2}, \frac{1}{2 n+1}\right)$ for $r \in N$. Let $T^{\prime}(R)$ be the usual topology and duf ine $I^{\prime}(X)$ tor he subgenerated by the subbasic open sets $\{\mathrm{V} \subseteq X-\{1\} \mid V \varepsilon T(R)\} U\left\{H_{r} U G \mid r \varepsilon N\right.$ and $1 \varepsilon G \in T(R)\} U\left\{X-\left(H_{r} U G\right) \mid r \varepsilon N\right.$ and $\left.1 \varepsilon G \varepsilon T(R)\right\}$. Let $T(Y)$ have subbasic open $\operatorname{sets}\{\mathrm{V} \subseteq \mathrm{Y}-\{1\} \mid \mathrm{V} \in \mathrm{T}(\mathrm{R})\} U\left\{G_{\mathrm{r}} \mathrm{U}\{0\} \mid \mathrm{r} \varepsilon \mathrm{N}\right\} \mathrm{U}\left\{\mathrm{H}_{\mathrm{r}} \mathrm{U} G \mid \mathrm{r} \varepsilon \mathrm{N}\right.$ and $\left.1 \in G \in \mathrm{T}(\mathrm{R})\right\}$. If $\mathrm{f}: \mathrm{X} \rightarrow \mathrm{Y}$ is the inclusion function, the graph of $\mathrm{f}, \mathrm{G}(\mathrm{f}) \subseteq \mathrm{X} \mathrm{x}$, is totally strongly closed but not totally extremely closed. For $(1,0) \notin G(f)$ and if $1 \varepsilon U \varepsilon T(X)$ and if $0 \in \quad V \in T_{\Theta}(Y)$ then $U \cap V \neq \emptyset$.

By Note $2, \mathrm{f}_{\mathrm{a}}: \mathrm{X}_{\mathrm{a}} \rightarrow \mathrm{Y}_{\mathrm{a}}$ is faintly continuous for each a $\varepsilon \mathrm{A}$ if and only if each $\mathrm{f}_{\mathrm{a}}: \mathrm{X}_{\mathrm{a}} \rightarrow\left(\mathrm{Y}_{\mathrm{a}}\right)_{\ominus}$ is continuous which holds if and only if $\mathrm{f}=\Pi \mathrm{f}_{\mathrm{a}}: \Pi \mathrm{x}_{\mathrm{a}} \rightarrow \Pi\left(\mathrm{Y}_{\mathrm{a}}\right)_{\ominus}$ is continuous. But for a family of functions $\left\{f_{a}: x_{a} \rightarrow Y_{a} \mid a \varepsilon A\right\}, f=\pi f_{a}$ is faintly continuous if and only if $f: \Pi x_{a} \rightarrow\left(\pi Y_{a}\right)_{\Theta}$ is continuous. These remarks establish the following.

Theorem 5. If $\pi \mathrm{f}_{\mathrm{a}}: \Pi \mathrm{X}_{\mathrm{a}} \rightarrow \Pi \mathrm{Y}_{\mathrm{a}}$ is faintly continuous then each $\mathrm{f}_{\mathrm{a}}: \mathrm{x}_{\mathrm{a}} \rightarrow \mathrm{Y}_{\mathrm{a}}$ is faintly continuous.

Example 3 strongly suggests that the converse of Theorem 5 does not hold.

Theorem 6. If $\mathrm{f}: \mathrm{X} \rightarrow \Pi \mathrm{Y}_{\mathrm{a}}$ is faintly continuous then each $\mathrm{P}_{\mathrm{a}} \circ \mathrm{f}$ is faintly continuous.

Proof: If $\mathrm{f}: \mathrm{X} \rightarrow\left(\mathrm{I} \mathrm{Y}_{\mathrm{a}}\right)_{\odot}$ is continuous then $\mathrm{f}: \mathrm{X} \rightarrow \Pi\left(\mathrm{Y}_{\mathrm{a}}\right)_{\ominus}$ is continuous which holds if and only if $P_{a} \circ f: X \rightarrow\left(Y_{a}\right)_{\odot}$ is continuous and this holds if and only if $\mathrm{P}_{\mathrm{a}} \circ \mathrm{f}: \mathrm{X} \rightarrow \mathrm{Y}_{\mathrm{a}}$ is faintly continuous.

Corollary 4. If $\left\{\mathrm{f}_{\mathrm{a}}: \mathrm{X} \rightarrow \mathrm{Y}_{\mathrm{a}} \mid \mathrm{a} \in \mathrm{A}\right\}$ is a family of functions and if $\mathrm{f}: \mathrm{X} \rightarrow \mathrm{II} \mathrm{Y}_{\mathrm{a}}$, defined by $f(x)=\left\{f_{a}(x)\right\}$, is faintly continuous, then each $f_{a}$ is faintly continuous.

Proof: For each a $\varepsilon \mathrm{A}, \mathrm{f}_{\mathrm{a}}=\mathrm{P}_{\mathrm{a}} \circ \mathrm{f}$.

\section{APPLiCATIONS.}

Firstly, Hausdorff and Urysohn spaces, $Y$, are characterized in terms of the diagonal set, $D(Y) \subseteq Y \times Y$.

Proposition 1. A space $Y$ is $T_{2}$ if and only if $D(Y)$ is strongly closed with respect to each factor.

Proof: If $Y$ is $T_{2}$ and $\left(y_{1}, y_{2}\right) \in(Y \times Y)-D(Y)$ then $y_{1} \neq y_{2}$ and there are disjoint open sets $v_{1}$ and $V_{2}$ containing $y_{1}$ and $y_{2}$ respectively. Thus $C 1 v_{1} \cap v_{2}=\emptyset=v_{1} \cap C 1 V_{2}$ so that $\left(C 1 V_{1} \times V_{2}\right) \cap D(Y)=\emptyset=\left(V_{1} \times C 1 V_{2}\right) \cap D(Y)$, showing that $D(Y)$ is strongly closed with respect to each factor of $Y x Y$. For the sufficiency, if $D(Y)$ is strongly closed, $D(Y)$ is closed so that $Y$ is $T_{2}$. 
Proposition 2. A space $\mathrm{Y}$ is $\mathrm{T}_{2 \frac{1}{2}}$ if and only if $\mathrm{D}(\mathrm{Y})$ is totally strongly closed.

Proof: Suppose first that $\mathrm{Y}$ is $\mathrm{T}_{2 \frac{1}{2}}$ and let $\left(\mathrm{y}_{1}, \mathrm{y}_{2}\right) \in(\mathrm{Y} \times \mathrm{Y})-\mathrm{D}(\mathrm{Y})$. Then $\mathrm{y}_{1} \neq \mathrm{y}_{2}$ and there exist open sets $V_{1}$ and $V_{2}$ containing $y_{1}$ and $y_{2}$ respectively with $\mathrm{Cl} \mathrm{V}_{1} \cap \mathrm{Cl} \mathrm{V}_{2}=\emptyset$. Thus $\left(\mathrm{C} 1 \mathrm{~V}_{1} \times \mathrm{Cl} \mathrm{V}_{2}\right) \cap \mathrm{D}(\mathrm{Y})=\emptyset$ showing that $\mathrm{D}(\mathrm{Y})$ is totally strongly closed. Conversely, if $\mathrm{D}(\mathrm{Y})$ is totally strongly closed and $\mathrm{y}_{1}, \mathrm{y}_{2} \varepsilon \mathrm{Y}$ with $y_{1} \neq y_{2}$ then $\left(y_{1}, y_{2}\right) \notin D(Y)$ so that for some open sets $V_{1}$ and $v_{2}$ containing $y_{1}$ and $y_{2}$ respectively, $\left(C 1 V_{1} \times C 1 V_{2}\right) \cap D(Y)=\emptyset$. Thus $C 1 V_{1} \cap C 1 V_{2}=\emptyset$ and $Y$ is $T_{2 \frac{1}{2}} \cdot$

Proposition 3. If $\mathrm{Y}$ is $\mathrm{T}_{3}$ then $\mathrm{D}(\mathrm{Y})$ is totally extremely closed.

Proof: If $\mathrm{Y}$ is $\mathrm{T}_{3}$ thus $\mathrm{Y}$ is regular and $\mathrm{T}_{2}$ so that $\mathrm{Y}=\mathrm{Y}_{\Theta}$ and $\mathrm{D}(\mathrm{Y})=\mathrm{D}\left(\mathrm{Y}_{\Theta}\right)$ is closed in $\mathrm{Y} \times \mathrm{Y}=\mathrm{Y}_{\Theta} \times \mathrm{Y}_{\Theta}$ and hence totally extremely closed.

Since there are Hausdorff non-Urysohn spaces, Propositions 1 and 2 show that strongly closed with respect to each a $\varepsilon$ B does not imply strongly closed with respect to $\mathrm{B}$.

Theorem 7. If $\mathrm{f}_{\mathrm{a}}: \mathrm{X}_{\mathrm{a}} \rightarrow \mathrm{Y}_{\mathrm{a}}$ is weakly (faintly) continuous for $\mathrm{a} \varepsilon \mathrm{B} \subseteq \mathrm{A}$ and continuous for $a \in A-B$ and if $E \subseteq \Pi Y_{a}$ is strongly (extremely) closed with respect to $B$, then $\left(\Pi \mathrm{f}_{\mathrm{a}}\right)^{-1}(\mathrm{E})$ is closed.

Proof: Suppose first that $\mathrm{E}$ is extremely closed with respect to $\mathrm{B} \subseteq \mathrm{A}$ and that $\mathrm{f}_{\mathrm{a}}$ is faintly continuous for $\mathrm{a} \varepsilon \mathrm{B}$, and continuous otherwise. Then $\Pi \mathrm{f}_{\mathrm{a}}: \Pi \mathrm{x}_{\mathrm{a}} \rightarrow \Pi_{\mathrm{a}}$ is continuous where $Z_{a}=\left(Y_{a}\right)_{\ominus}$ for $a \varepsilon B$ and $Z_{a}=Y_{a}$ otherwise. Further, $E$ is closed in $\Pi \mathrm{Z}_{\mathrm{a}}$ so that $\left(\Pi \mathrm{f}_{\mathrm{a}}\right)^{-1}(\mathrm{E})$ is closed. Now, suppose that $\mathrm{f}_{\mathrm{a}}$ is weakly continuous for a $\varepsilon B$ and continuous otherwise and that $E$ is strongly closed with respect to $B$. Then if $\mathrm{x}=\left\{\mathrm{x}_{\mathrm{a}}\right\} \notin\left(\Pi \mathrm{f}_{\mathrm{a}}\right)^{-1}(\mathrm{E})$ then $\mathrm{y}=\left\{\mathrm{f}_{\mathrm{a}}\left(\mathrm{x}_{\mathrm{a}}\right)\right\} \notin \mathrm{E}$. Thus there exists a basic open set $I \mathrm{~V} \mathrm{~V}_{\mathrm{a}}$ containing $\mathrm{y}$ such that $\Pi \mathrm{W}_{\mathrm{a}} \cap \mathrm{E}=\emptyset$ where $\mathrm{W}_{\mathrm{a}}=\mathrm{C} 1 \mathrm{~V}_{\mathrm{a}}$ for $\mathrm{a} \varepsilon \mathrm{B}$ and $\mathrm{W}_{\mathrm{a}}=\mathrm{V}_{\mathrm{a}}$ otherwise. Hence $x \in\left(\Pi \mathrm{f}_{\mathrm{a}}\right)^{-1}\left(\Pi \mathrm{V}_{\mathrm{a}}\right)=\Pi\left(\mathrm{f}_{\mathrm{a}}^{-1}(\mathrm{Va})\right) \subseteq \Pi \operatorname{Int} \mathrm{f}_{\mathrm{a}}^{-1}\left(\mathrm{~W}_{\mathrm{a}}\right)=\operatorname{Int} \Pi\left(\mathrm{f}_{\mathrm{a}}^{-1}(\mathrm{Wa})\right)=$ Int $\left(\Pi \mathrm{f}_{\mathrm{a}}\right)^{-1}\left(\Pi \mathrm{w}_{\mathrm{a}}\right) \subseteq\left(\Pi \mathrm{f}_{\mathrm{a}}\right)^{-1}\left(\Pi \mathrm{w}_{\mathrm{a}}\right) \subseteq \Pi \mathrm{x}_{\mathrm{a}}-\left(\Pi_{\mathrm{f}} \mathrm{f}^{-1}(\mathrm{E})\right.$. Thus $\left(\Pi \mathrm{f}_{\mathrm{a}}\right)^{-1}(\mathrm{E})$ is closed. If, in Theorem 7, B = A, the second part of the proof is simpler since $E$ is totally strongly closed if and only if $E$ is $\theta$-closed in which case $\left(\pi f_{a}\right)^{-1}(E)$ is closed if $\pi f_{a}$ is only faintly continuous but by Theorem 1 , $\pi f_{a}$ is weakly continuous if each $f_{a}$ is weakly continuous. In fact, one might question whether the weak continuity of $f_{a}$ for a $\varepsilon B$ might be replaced with faint continuity. But recall the Example 3 indicates the likelihood that in that case $\pi \mathrm{f}_{\mathrm{a}}$ may fail to be faintly continuous.

Corollary 4. [1] If $Y$ is Hausdorff and $f: X \rightarrow Y$ is weakly continuous then $f$ has a closed graph, $G(f) \subseteq X \times Y$.

Proof: Let $i: Y \rightarrow Y$ be the continuous identity function. If $Y$ is $T_{2}, D(Y) \subseteq Y \times Y$ is strongly closed with respect to the first factor so that by Theorem 7 , if $f$ is weakly continuous, $G(f)=(f \times i)^{-1}(D(Y))$ is closed.

Corollary 5. [2] If $\mathrm{Y}$ is Urysohn and $\mathrm{f}: \mathrm{X} \rightarrow \mathrm{Y}$ is a weakly continuous injection then $\mathrm{X}$ is Hausdorff.

Proof: By Proposition 2, $D(Y)$ is totally strongly closed if $Y$ is Urysohn and by Theorem 7, ( $\mathrm{f} \times \mathrm{f})^{-1}(\mathrm{D}(\mathrm{Y}))$ is closed if $\mathrm{f}$ is weakly continuous. If also $\mathrm{f}$ is injective, $(f \times f)^{-1}(D(Y))=D(X)$ is closed so that $X$ is Hausdorff. Baker [3] noted by Example 1 that Corollary 5 is not true if weak continuity is reduced to subweak continuity. In particular, this shows that Theorem 7 does not hold with weak continuity replaced by 
subweak continuity. However, Baker [3] proved that Corollary 4 can be strengthened by replacing weak continuity with subweak continuity. This is subweakly continuous functions into Hausdorff spaces have closed graphs. Apparently, Theorem 7 cannot be used to obtain Baker's improved version of Corollary 4, so that results obtained through Theorem 7 may not be "sharp" or "optimum". Some consequences of the improved version of Corollary 4 follow.

Proposition 4. If $X$ is compact, $Y$ is Hausdorff and $f: X \rightarrow Y$ is subweakly continuous (and bijective) then $f$ is closed (and open).

Proof: Let $X$ be compact, $Y$ be Hausdorff and $f: X \rightarrow Y$ be subweakly continuous. Then closed subsets of $X$ are compact and have closed images under $f$ since the graph of $f$ is closed. If $f$ also preserves complements, $f$ is also open.

Proposition 5. If $Y$ is Hausdorff and $f: X \rightarrow Y$ is a subweakly continuous bijection then $\mathrm{f}^{-1}$ is c-continuous [16] (i.e. $\mathrm{f}(\mathrm{V})$ is open if $\mathrm{X}-\mathrm{V}$ is closed and compact).

Proof: Long and Hendrix [17] showed that every closed graph function is c-continuous. If $\mathrm{f}$ is bijective with a closed graph then the graph of $\mathrm{f}^{-1}$ is closed. Proposition 5 improves a result of [17] by replacing almost continuity (in the sense of Singal and Singa1) with subweak continuity.

Proposition 6. [3] If $\mathrm{Y}$ is Hausdorff and $\mathrm{f}: \mathrm{X} \rightarrow \mathrm{Y}$ is a subweakly continuous inection then $\mathrm{X}$ is $\mathrm{T}_{1}$.

Proof: In the graph of $f, G(f) \subseteq X \times Y$, is closed and $f$ is injective then for each $x \in X,\{x\}=f^{-1}(f(x))$ is closed since $\{f(x)\}$ is compact.

Since subweakly continuous functions into Hausdorff spaces have closed graphs, they are c-continuous. (Inverse images of open complements of compact sets are open.) Thus Proposition 6 follows from the result of Long and Hendrix [17] that c-continuous injections into a $\mathrm{T}_{1}$ space must have a $\mathrm{T}_{1}$ domain.

Proposition 7. If $\mathrm{f}: \mathrm{X} \rightarrow \mathrm{X}$ has a closed graph, $G(f)$, then $F=\{x \in X \mid f(x)=x\}$, the set of fixed points for $f$, is closed.

Proof: Let $x \in C l F$ and let $\left\{x_{a}\right\}$ be a net in F with $x_{a} \rightarrow x$. Then $\left\{\left(x_{a}, x_{a}\right)\right\}$ is a net in $G(f)$ and $\left(x_{a}, x_{a}\right) \rightarrow(x, x)$. Thus $x \in F$ if $G(f)$ is closed.

Corollary 6. [3] If $A$ is a subweak1y continuous retract of a Hausdorff space then A is closed.

Proof: A retract is the set of fixed points for the retraction.

Corollary 7. If $\mathrm{A}$ is a c-continuous retract of a locally compact Hausdorff space, then $\mathrm{A}$ is closed.

Proof: From [17], c-continuous functions into locally compact Hausdorff spaces have closed graphs.

\section{REFERENCES}

1. NOIRI, T. "Between Continuity and Weak Continuity," Boll. un. Mat. Inta1., 9 (1974), 647-654.

2. NOIRI, T. "On Weakly Continuous Mappings," Proc. Am. Math. Soc., 46 (1974), 120-124.

3. BAKER, C.W. "Yroperties of Subweak1y Continuous Functions," Yokohama Math. J., to appear. 
4. VELiCKO, N.V. "H-Closed Topological Spaces" Math. Sb., 70 (1966), 98-112, or Amer. Math. Soc. Translations, 78 (1968), 103-118.

5. DICKMAN, R.F. and PORTER, J.R. " $\Theta-C l o s e d$ Subsets of Hausdorff Spaces," Pacific J. of Math., 59 (1975), 407-415.

6. JOSEPH, J.E. "On H-Closed Spaces," Proc. Am. Math. Soc., 55 (1976), 223-226.

7. LEVINE, N. "A Decomposition of Continuity in Topological Spaces," Amer. Math. Monthly, 68 (1961), 44-46.

8. LONG, P.E. and HERRINGTON, L.L. "The $T_{\theta^{-T o p o l o g y}}$ and Faintly Continuous Functions," Kyungpook Math. Journal, 22 (1982), 7-14.

9. ROSE, D.A. "Weak Continuity and Almost Continuity," International Journa1 of Math. and Math Sciences, to appear.

10. SINGAL, M.K. and SINGAL, A.R. "Almost-Continuous Mappings," Yokohama Math. Journal, 16 (1968), 63-73.

11. FOMIN, S., "Extensions of Topological Spaces," Ann. Math., 44 (1943), 471-480.

12. NOIRI, T. "A Remark on Almost-Continuous Mappings," Proceedings of the Japan Academy, 50 (1974), 205-207.

13. LONG, P.E. and HERRINGTON, L.L. "Properties of Almost-Continuous Functions," Bollettino un. Mat. Ita1., 10 (1974), 336-342.

14. NOIRI, T. "Properties of O-Continuous Functions," Accademia Nazionale Dei Lincei (Rendiconti), 58 (1975), 887-891.

15. LONG, P.E. and HERRINGTON, L.L., "Functions with Strongly-Closed Graphs," Bol1. un. Mat. Ital., 12 (1975), 381-384.

16. GENTRY, K.R. and HOYLE III, HUGHES, B. "C-Continuous Functions," Yokohama Math. Journa1 18 (1970), 71-76.

17. LONG, P.E. and Hendrix, M.D. "Properties of C-Continuous Functions," Yokohama Math. Journa1 22 (1974), 117-123. 


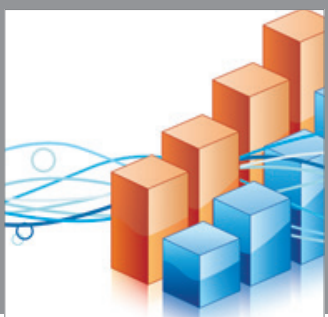

Advances in

Operations Research

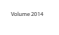

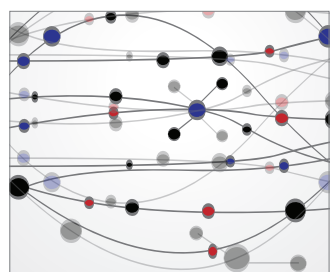

\section{The Scientific} World Journal
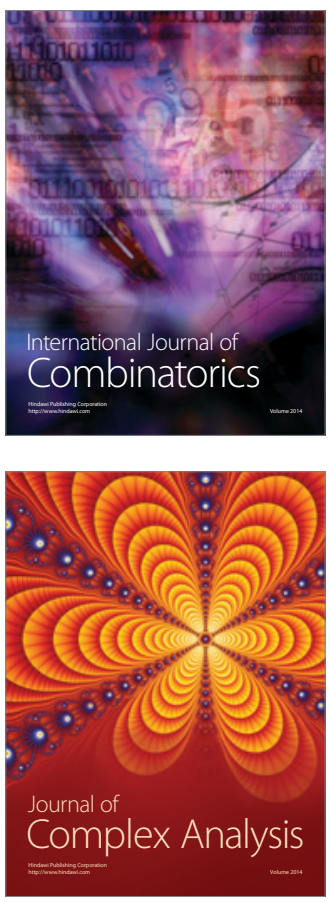

International Journal of

Mathematics and

Mathematical

Sciences
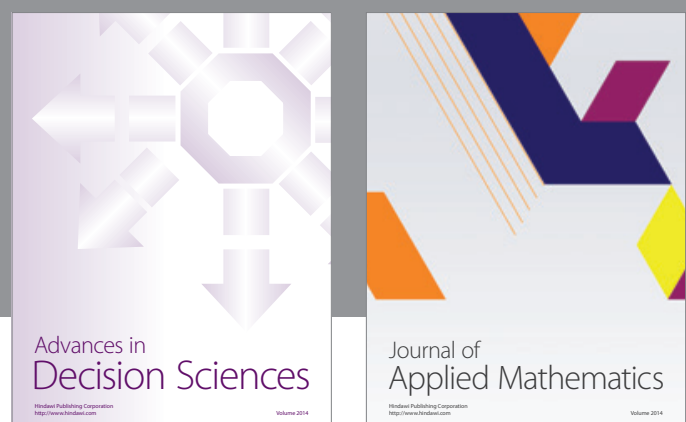

Journal of

Applied Mathematics
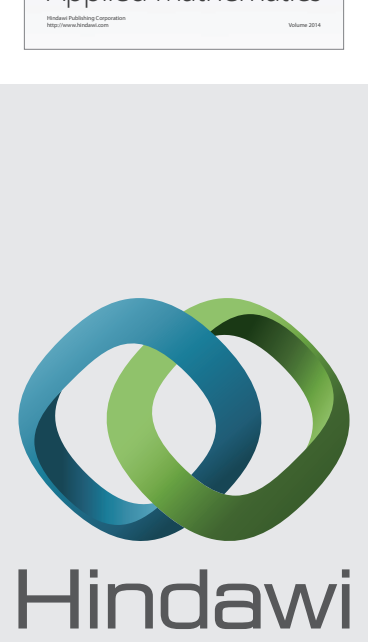

Submit your manuscripts at http://www.hindawi.com
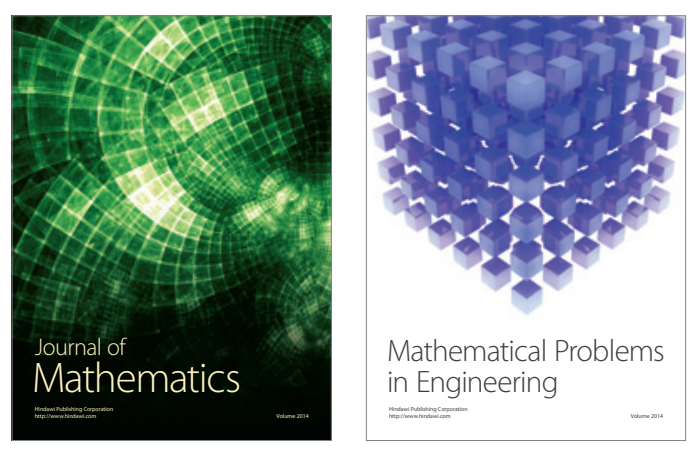

Mathematical Problems in Engineering
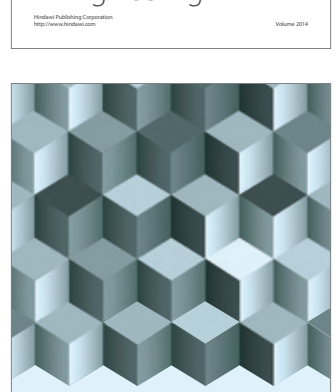

Journal of

Function Spaces
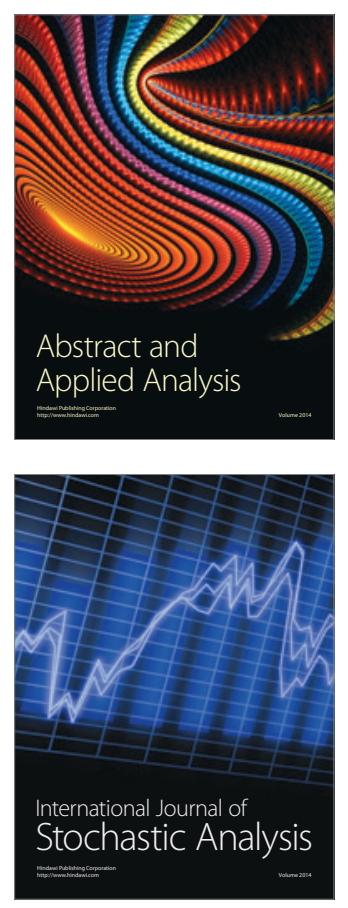

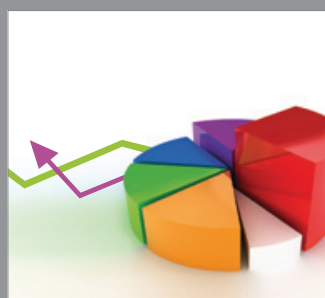

ournal of

Probability and Statistics

Promensencen
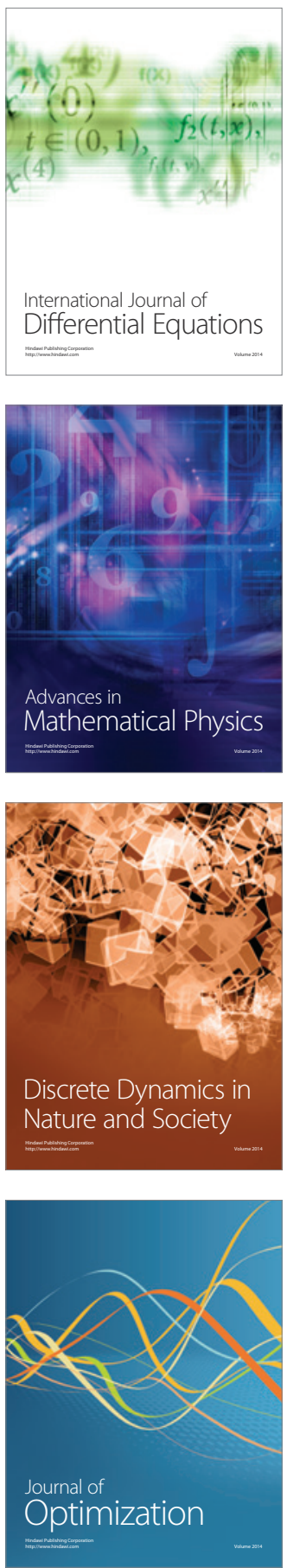